\title{
Pathways in the Diagnosis and Management of Diabetic Polyneuropathy
}

\author{
Michelle Kaku $^{1}$ - Aaron Vinik ${ }^{2}$ - David M. Simpson ${ }^{1}$ \\ Published online: 22 April 2015 \\ (C) The Author(s) 2015. This article is published with open access at Springerlink.com
}

\begin{abstract}
Distal symmetric polyneuropathy (DSPN), the most common form of diabetic neuropathy, has a complex pathophysiology and can be a major source of physical and psychologic disability. The management of DSPN can be frustrating for both patient and physician. This article provides a general overview of typical patient pathways in DSPN, and highlights variations in diagnosis, management, and referral patterns among different providers. DSPN is managed in several settings by primary care physicians (PCPs), specialists, and nurse practitioners. The initial clinical management of the patient is often dependent on the presenting complaint, the referral pattern of the provider, level of comfort of the PCP in managing diabetic complications, and geographic access to specialists. The primary treatment of DSPN focuses mainly on glycemic control and adjustment of modifiable risk factors, but other causes of neuropathy should also be investigated. Several pharmacologic agents are recommended by treatment guidelines, and as DSPN typically exists with comorbid conditions, a multimodal therapeutic approach should be considered. Barriers to effective management include failure to recognize DSPN, and misdiagnosis. Patient education also remains important. Referral patterns vary widely according to geographic location, access to services, provider preferences, and comfort in managing complex aspects of the
\end{abstract}

This article is part of the Topical Collection on Pharmacologic Treatment of Type 2 Diabetes

Aaron Vinik

vinikai@evms.edu

1 Department of Neurology, Icahn School of Medicine at Mount Sinai, New York, NY, USA

2 Eastern Virginia Medical School, Strelitz Diabetes Research Institute, 855W. Brambleton Avenue, Norfolk, VA 23510, USA disease. The variability in patient pathways affects patient education, satisfaction, and outcomes. Standardized screening tools, a multidisciplinary team approach, and treatment algorithms for diabetic neuropathy should improve future care. To improve patient outcomes, DSPN needs to be diagnosed sooner and interventions made before significant nerve damage occurs.

Keywords Distal symmetric polyneuropathy · Diabetic · Neuropathy $\cdot$ Diagnosis · Treatment algorithm ·

Multidisciplinary

\section{Introduction}

Peripheral neuropathy affects $26 \%$ to $47 \%$ of people with diabetes in the USA [1]. The most common form of diabetic neuropathy is distal symmetric polyneuropathy (DSPN), occurring in up to $50 \%$ of patients with neuropathy. The pathophysiology of DSPN is complex and its management can be frustrating for both the patient and the physician. DSPN can be a major source of disability, both physically and psychologically, and is an independent risk factor for depressive symptoms [2]. High pain levels are associated with poor sleep, functioning, and productivity [3]. Direct and indirect costs, including prescription medications and office visits, are also significantly higher among patients with greater pain severity [3].

The estimated annual cost of diabetic neuropathy and its complications in the USA in 2003 was between $\$ 4.6$ and $\$ 13.7$ billion [4]. Although diabetic neuropathy is often thought of as an adult disease, neuropathy has been reported in $11 \%$ of youths with type 1 diabetes, and may occur sooner after diagnosis in children with type 2 diabetes $[5,6]$. This review assesses typical patient pathways in DSPN and 
identifies variations in diagnosis, management, and referral patterns among different providers.

\section{Materials and Methods}

Literature searches were carried out from the beginning of 2010 to June 2014 to identify published evidence on DSPN and its management. PubMed was searched using the terms '(diabetic OR diabetes) AND (neuropathy OR pain)' while congresses of the European Association for the Study of Diabetes, American Diabetes Association, and International Diabetes Federation were searched using 'neuropathy', 'pain', 'PDN', and 'DSPN'. All abstract titles were assessed for papers of relevance.

\section{Types of Neuropathy}

There are typical and atypical forms of DSPN [7, 8]. The Toronto Consensus Panel on Diabetic Neuropathy defined typical DSPN as a "chronic, symmetrical, length dependent sensorimotor polyneuropathy" [9]. Atypical DSPN has a monophasic or fluctuating course and may have asymmetric or proximal symptoms, as well as motor involvement. Acute painful DSPN has been characterized as an additional subtype that presents predominantly with pain, particularly sharp, stabbing, and electric-shock sensations in the distal extremities that may include nocturnal exacerbations [10]. Such painful small-fiber neuropathy, with minimal objective neurologic signs, may occur in prediabetes [11]. Other atypical forms of neuropathy that occur in diabetes include focal and multifocal neuropathies, such as mononeuropathies, cranial neuropathies, plexopathies, radiculopathy, mononeuritis multiplex, amyotrophy, predominantly small-fiber neuropathy, and autonomic neuropathy. Chronic inflammatory demyelinating neuropathy is also more common in diabetic than in non-diabetic patients [12].

\section{Symptoms and Clinical Features}

The most common symptoms of DSPN are length dependent, usually affecting the feet first and progressing proximally. Symptoms are predominantly sensory and can be classified as "positive" (tingling, burning, and other abnormal sensations) or "negative" (sensory loss, weakness, numbness, and unsteady gait). Painful DSPN is often described as burning or electric and tends to occur more often at night. Motor symptoms are less common but can occur later in the disease course. Distal deep-tendon reflexes are typically reduced or absent.

The most serious complications of DSPN include foot ulcers, Charcot foot abnormalities, injuries, and ultimately, lower-extremity amputation, especially when concomitant peripheral vascular disease causes foot ischemia. Degradation of sensory function leading to imbalance and unsteadiness in gait [13] with loss of proprioception results in increased likelihood of a fall [14]. Decreased sensation of the distal extremities makes small injuries and ulcers common, and more than $2 \%$ of patients with diabetes develop new foot ulcers each year [15]. The lifetime risk that a patient with diabetes will acquire a foot lesion, including an ulcer or gangrene, is estimated to be approximately $15 \%$ to $25 \%$ [16]. The chronic nature of DSPN can lead to anxiety, depression, catastrophizing behavior, an inability to accept chronic pain, and sleep disturbances [17].

\section{Risk Factors for DSPN}

The most important risk factor for developing DSPN in type 1 diabetes is poor glycemic control. In the Diabetes Control and Complications Trial, intensive therapy reduced development of clinical neuropathy by $64 \%$ compared with standard glucose control over 5 years [18]. In the Epidemiology of Diabetes Interventions and Complications follow-up study, the benefits of intensive insulin treatment persisted for 14 years, despite similar glycemic control between the groups following study completion $[19,20 \bullet \cdot$. The EURODIAB IDDM Complications Study found additional correlations between neuropathy and duration of type 1 diabetes, quality of metabolic control, age, height, cigarette smoking, high-density lipoprotein cholesterol, proliferative diabetic retinopathy, and cardiovascular disease [21].

Risk factors for DSPN in type 2 diabetes are similar to the risks for vascular disease, such as smoking, obesity, hyperlipidemia, age, and waist circumference. Many of these risk factors are modifiable, highlighting the importance of patient self-motivation and the potential influence of physician counseling in determining disease progression. Among prediabetic patients, increased fasting glucose and impaired glucose tolerance are associated with a high risk of clinical DSPN, comparable with that of diabetic patients [22, 23], highlighting the need for early therapeutic intervention. In patients with neuropathy associated with impaired glucose tolerance, partial cutaneous re-innervation is possible through improvements to diet and exercise after counseling [24]. The United Kingdom Prospective Diabetes Study found a reduced risk of neuropathy with intensive treatment compared with standard glycemic control [25]. This reduced risk must be weighed against the potential risk of overly aggressive glycemic control, which may be associated with acute painful DSPN [26] and increased cardiovascular risk and sudden death related to autonomic dysfunction [27-29]. 


\section{Pathophysiology}

The pathophysiology of DSPN is not fully understood and is likely multifactorial. Nerve biopsy from patients with painful neuropathy indicates that there is degeneration of myelinated and unmyelinated fibers [30, 31]. Metabolic derangements have been implicated, such as oxidative and nitrosative stress, accumulation of glycation end products, impaired calcium homeostasis, and mitochondrial dysfunction [32-34], and increased activity through the polyol pathway [35]. Impaired insulin signaling may directly injure the dorsal root ganglia and play a role in the pathogenesis [36]. The mechanisms involved in metabolic syndrome may contribute to a selfperpetuating cycle of oxidative and nitrosative stress, inflammatory signals, and disruption of normal cellular function $[37 \bullet, 38 \bullet$. Peripheral lesions may also have central effects, particularly through central sensitization of nociceptive neurons [39].

\section{Diagnosis}

Diagnosis of DSPN is primarily clinical and involves a thorough history and physical examination with a focus on cardiovascular and neurologic tests, and a detailed assessment of the feet [40]. Early diagnosis of DSPN is imperative in preventing irreversible damage; however, $50 \%$ of patients may be asymptomatic. A 1-g Semmes-Weinstein monofilament is useful for detecting changes in sensitivity [41], and a $10-\mathrm{g}$ monofilament is useful for predicting ulcer risk. A small decrease in the duration of a vibratory stimulus sensation, assessed with a $128-\mathrm{Hz}$ tuning fork, is an early indicator of neuropathy. A more quantitative vibration assessment is available using the Rydel-Seifer tuning fork. The hallux, as opposed to the fifth metatarsal head, is a more sensitive indicator of neuropathy in patients with diabetes [42]. A careful examination of the foot should include a check for peripheral pulses, to assess for peripheral vascular disease, and a visual check for ulcers. As painful diabetic peripheral neuropathy (pDPN) is usually symmetrical, patients with asymmetrical symptoms or signs should be carefully assessed for other etiologies of their symptomatology [9].

Nerve conduction studies (NCS) often form part of the evaluation of DSPN, especially in atypical cases with superimposed nerve entrapment or inflammatory demyelinating neuropathy and in patients with minimal or no objective neurologic signs. While NCS are helpful in diagnosing patients with large-fiber neuropathy, they have limited utility in diagnosing small-fiber neuropathy. Small-fiber function may be assessed by skin biopsy and quantitation of intra-epidermal nerve fiber density, particularly when results of NCS are normal. Skin biopsy is a minimally invasive procedure [43-46]. Decreased intra-epidermal nerve fiber density is indicative of small-fiber neuropathy. Further imaging, such as computed tomography or magnetic resonance imaging, is usually not necessary unless there is clinical suspicion for nerve entrapment or disc pathology.

As DSPN is a diagnosis of exclusion, other etiologies of polyneuropathy should also be assessed: alcohol use; vitamin B12 levels; vasculitis; serum protein electrophoresis and immunofixation; infections (e.g., Lyme disease, HIV); and cancer and related paraneoplastic syndromes [47]. For example, patients with vitamin B12 deficiency have impaired sensory and motor peripheral nerve function [48]. Notably patients may have functional consequences of vitamin B12 deficiency even with levels in the "low normal" range, and should receive supplementation with methylcobalamin [48]. Metformin may contribute to vitamin deficiency [49].

The Toronto Consensus Panel on Diabetic Neuropathy defined specific diagnostic guidelines that estimate the severity of DSPN based on NCS and various signs and symptoms [50]. Additionally, questionnaires are frequently used to identify and quantify neuropathy including the Michigan Neuropathy Screening Instrument [51], the McGill Pain Questionnaire [52], the Neuropathic Pain Questionnaire [53], the Brief Pain Inventory [54], the Neuropathic Pain Symptom Inventory [55], the Norfolk Quality of Life Questionnaire-Diabetic Neuropathy Questionnaire [56], and the Neuropathy and Foot Ulcer-specific Quality of Life Instrument [57]. Standardized screening tools provide a good clinical record for posttreatment follow-up, are simple to use, and are easily administered by a physician assistant, nurse practitioner, or selfcompleted by the patient before the office visit [58].

\section{Treatment}

The focus of DSPN management is disease modification and symptomatic relief; no treatment completely prevents or reverses disease progression. Pancreas transplants [59], diet and exercise [24], and topiramate [60] have all been shown to induce small-fiber regeneration. Rational glycemic control is the primary approach to manage symptoms and prevent further damage, including falls and foot ulcers. Most clinical trials have studied therapies for symptomatic pain relief. Although various treatment approaches are recommended by diabetic and national societies, this review focuses on pharmacologic agents for symptomatic treatment. Duloxetine, pregabalin, and tapentadol are Food and Drug Administration (FDA)-approved medications for DSPN, although many other agents have been studied and are frequently used. To achieve an optimal therapeutic outcome, it is important to identify and treat any comorbid conditions. Some treatments may improve pain and sleep by direct and indirect pathways. Many treatments for DSPN require careful dose titration every $2-4$ weeks based on efficacy and safety. Combinations may also be useful, although consideration of potential drug-drug interactions 
is important, and combining first-line agents is not backed by trial evidence [61•].

Various organizations, professional societies, and expert panels have produced guidelines for the treatment of neuropathic pain including DSPN, such as the Toronto Consensus Panel on Diabetic Neuropathy [61 ${ }^{\bullet}$, the Neuropathic Pain Special Interest Group (NeuPSIG) [62], the European Federation of Neurological Societies Task Force [63], the National Institute for Health and Care Excellence (NICE) [64], the American Association of Neurology (AAN) in collaboration with the American Association of Neuromuscular and Electrodiagnostic Medicine and the American Academy of Physical Medicine and Rehabilitation [65], the Working Group on the Diabetic Foot from the French-Speaking Society of Diabetology [66], and the American Association of Clinical Endocrinologists [67]. Several of these were compared in a review by Spallone [68]; guidelines generally recommend considering tricyclic antidepressants (TCAs), serotonin/ norepinephrine-reuptake inhibitors (SNRIs), and alpha-2delta ligands as first-line agents. Many guidelines also recommend duloxetine as a first-line option.

\section{Tricyclic Antidepressants}

TCAs are commonly used agents for DSPN and their analgesic effect is likely to be mediated through a different pathway from their antidepressant effect. Anticholinergic and cardiac side effects are the biggest limitation to their use. Imipramine and desipramine have a lower side-effect burden than amitriptyline. The NeuPSIG guideline recommends TCAs as firstline agents, although they urge caution when using them in patients with ischemic cardiac disease or ventricular conduction abnormalities, suggesting a screening electrocardiogram in patients aged $\geq 40$ years and limiting doses to $<100 \mathrm{mg}$ /day [69]. The NICE guideline focuses on pharmacologic recommendations in the non-specialist setting and also includes amitriptyline among their list of first-line agents [64]. The clinical characteristics of these TCAs are summarized in Table 1.

\section{Serotonin/Norepinephrine-Reuptake Inhibitors}

SNRIs, such as duloxetine and venlafaxine, regulate descending inhibitory pain pathways by inhibiting the reuptake of serotonin and norepinephrine. In several clinical trials, duloxetine has been shown to be efficacious for up to a year [71]. The most common adverse effects of duloxetine include nausea, whereas for venlafaxine they are gastrointestinal disturbances. The NeuPSIG guideline recommends SNRIs as first-line agents. They suggest caution in patients with cardiac disease and advise a tapering schedule upon discontinuation of the drug to prevent withdrawal [69]. The NICE guideline recommends duloxetine as a first-line option; however, venlafaxine is not recommended [64]. The AAN guideline concludes that existing data are insufficient to recommend amitriptyline, venlafaxine, or duloxetine over one another [65]. The clinical characteristics of these SNRIs are summarized in Table 2.

\section{Anticonvulsants}

Anticonvulsants have a long history in the treatment of neuropathic pain. However, studies are sparse and results are inconsistent. Carbamazepine, oxcarbazepine, and lamotrigine block sodium channels and reduce neuronal excitability in the peripheral and central nervous system. Carbamazepine was one of the first antiepileptic drugs studied and had some success in reducing pain in several small studies $[72,73]$. The most common side effects include dizziness, ataxia, sedation, hyponatremia, blurred vision, and confusion in the elderly.

Some studies of lamotrigine report significant relief of pDPN $[74,75]$, while others have failed to show any significant benefit either as monotherapy [76] or as an adjunctive treatment [77]. The most concerning, albeit uncommon, side effect of lamotrigine is Stevens-Johnson syndrome, whereas more common side effects include sedation, dizziness, and ataxia.

The AAN guidelines conclude that sodium valproate should be considered for the treatment of peripheral diabetic neuropathy, whereas lamotrigine, oxcarbazepine, and lacosamide should probably not be considered [65]. They also conclude that there is insufficient evidence to support or refute the use of topiramate. However, some evidence suggests that topiramate can induce skin intra-epidermal nerve fiber regeneration and enhance neurovascular function [60].

Pregabalin and gabapentin are active at the alpha-2delta subunit of calcium channels; they decrease calcium influx, thereby decreasing central sensitization [63, 70]. As they are eliminated through the kidney and not the liver, the risk of drug-drug interactions is minimized. Both medications require titration schedules, and side effects include somnolence, dizziness, weight gain, headache, dry mouth, and peripheral edema. Pregabalin is the only medication that was given a level A recommendation by the AAN guidelines [65]; gabapentin was given a level B recommendation. Pregabalin and gabapentin are also both recommended as initial treatments for neuropathic pain in the NICE guidelines [64]. Improvements in patient function and quality of life in response to pregabalin treatment are correlated with the extent of pain relief [78]. However, rather than being mediated solely through pain relief, these improvements may also result from a combined effect on pain and sleep disturbance and a direct effect on patient function. The clinical characteristics of these anticonvulsants are summarized in Table 3. 


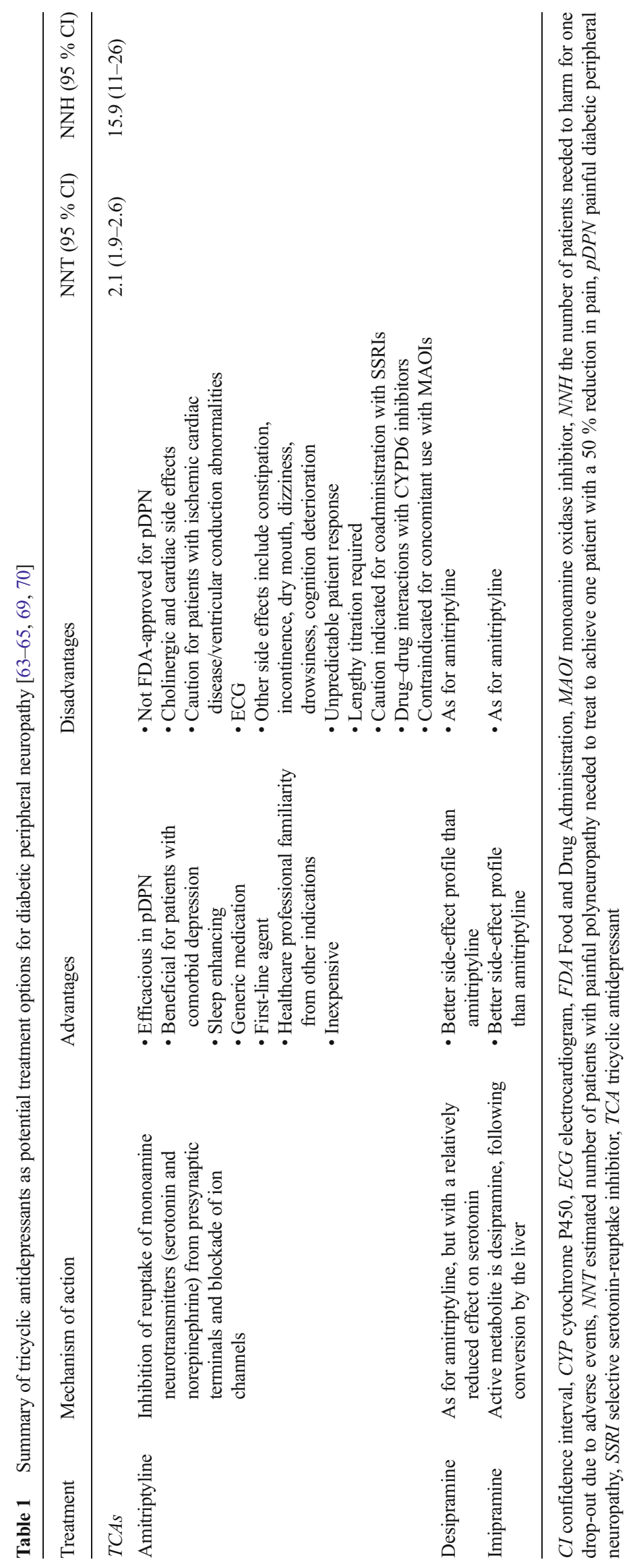




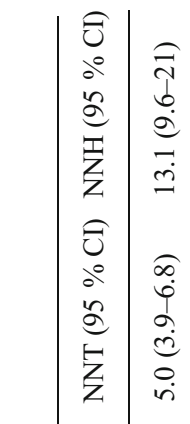

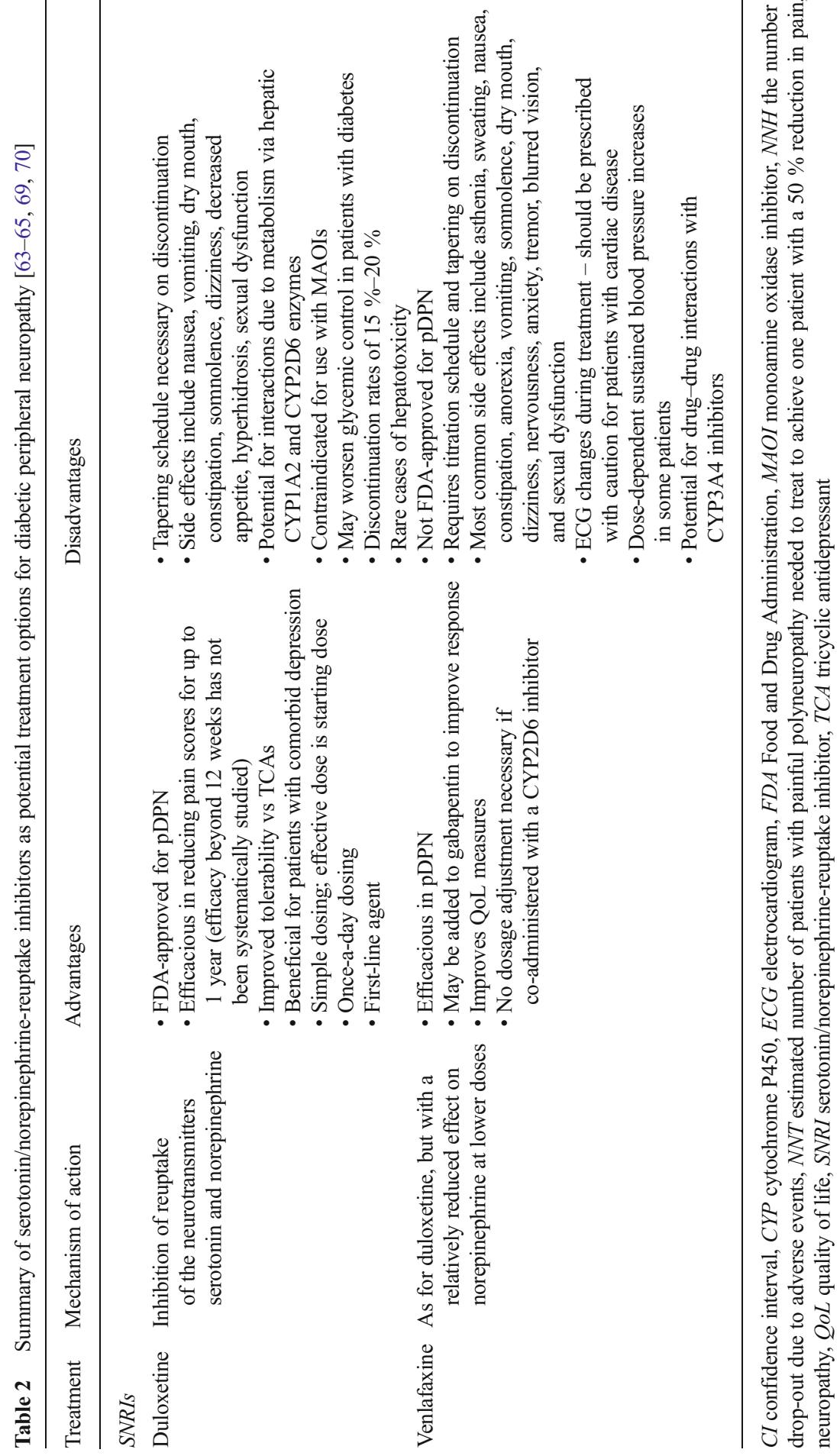




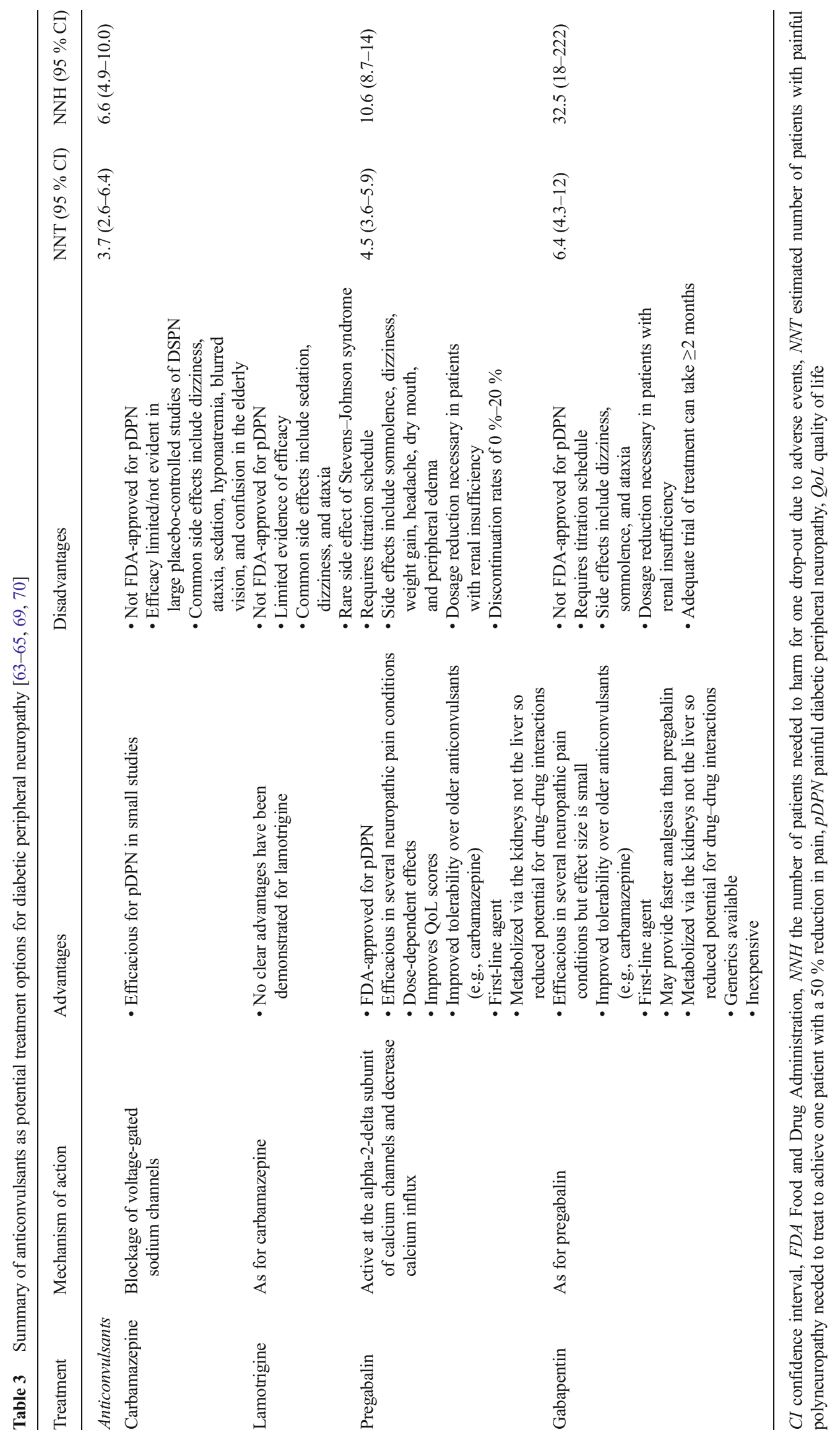




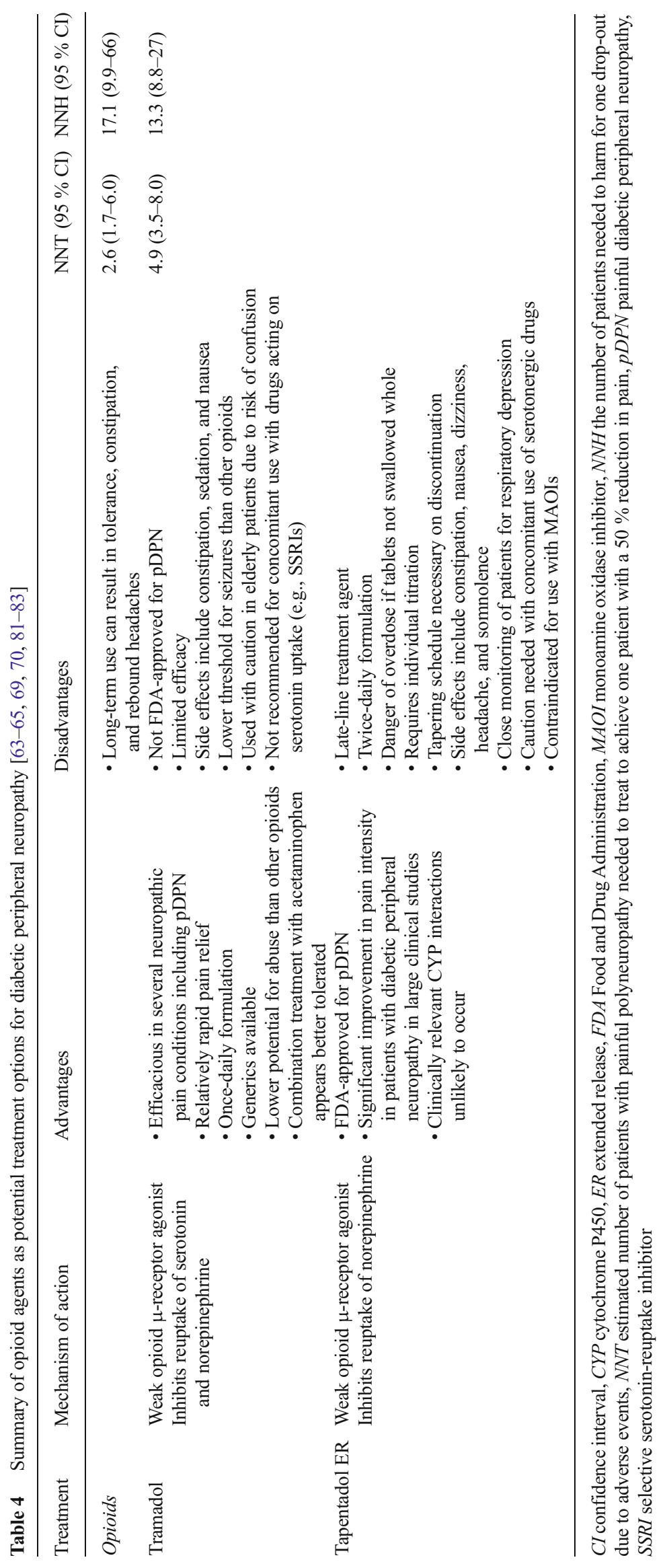




\section{Opioids}

Chronic opioid use can lead to tolerance, dependence, constipation, and rebound headaches. Tramadol has a low affinity for $\mu$-receptors and is a weak inhibitor of norepinephrine and serotonin reuptake, and moderately relieves DSPN-associated pain $[79,80]$. Its side-effect profile includes constipation, sedation, and nausea. Tramadol has a lower potential for abuse than many opioids, although it can also lower the seizure threshold. Tapentadol, an FDA-approved agent for painful DSPN, combines a dual mechanism of action in a single formulation by combining an opioid agonist and a norepinephrine antagonist, which provides effective analgesia in patients with DSPN [81-83].

The NeuPSIG guidelines suggest opioids should be reserved for patients who do not respond to first-line medications, although they are recommended for acute neuropathic pain, neuropathic pain due to cancer, episodic exacerbations of severe neuropathic pain, and if necessary when titrating one of the first-line agents [69]. The AAN guidelines suggest that morphine sulfate, tramadol, and oxycodone controlled-release are probably effective in lessening the pain of DSPN [65]. An ultra-rapid acting fentanyl effervescent buccal tablet provides rapid relief of breakthrough pain in patients with diabetic and other forms of neuropathic pain [84].

Several studies indicate that rational combination therapy improves efficacy versus monotherapy without significantly increasing adverse effects [85-88]. For example, gabapentin plus long-acting morphine sulfate appears to be superior to either drug alone [87]. Prolonged-release oxycodone appears to enhance the analgesic effects of gabapentin [86], although low-dose oxycodone does not appear to improve analgesia with pregabalin [88]. Tramadol plus acetaminophen appears to provide comparable pain relief to gabapentin alone [85]. The clinical characteristics of these opioids are summarized in Table 4.

\section{Cannabinoids}

Smoked cannabis provides pain relief in HIV-associated neuropathy $[89,90]$. However, cannabis oromucosal spray
(Sativex ${ }^{\circledR}$ ) was not effective in a small study of patients with painful polyneuropathy [91]. Side effects include headache, dizziness, somnolence, dry mouth, constipation, and diarrhea. Regulatory and legal obstacles further complicate the use of cannabinoids for neuropathic pain. The clinical characteristics of cannabis are summarized in Table 5.

\section{Thioctic Acid}

The antioxidant alpha-lipoic acid (thioctic acid) prevents progression of neuropathic impairments and improves neuropathic sensory symptoms including pain [92-94]. Although not all trials were conclusive and some were of poor methodologic quality, meta-analyses demonstrate that intravenous alphalipoic acid treatment is associated with significant short-term pain relief and improvements in nerve conduction [92, 95].

\section{Topical Agents}

\section{Capsaicin}

Capsaicin is a transient receptor potential vanilloid type 1 (TRPV1) agonist. Capsaicin creams (0.025-0.075\%) decrease pain in DSPN $[96,97]$. The NICE guidelines recommend considering the use of capsaicin cream for patients with localized neuropathic pain who wish to avoid or cannot tolerate oral treatments [64]. The AAN recommends considering capsaicin for the treatment of pDPN (level B recommendation) [69].

A high-concentration $8 \%$ capsaicin patch, administered for 60 minutes by a healthcare professional, provides at least 12 weeks of pain relief in controlled studies of post-herpetic neuralgia (PHN) [98, 99] and HIV-associated DSPN [100]. A meta-analysis of six studies of patients with PHN or painful HIV-associated DSPN confirmed that the high-concentration $8 \%$ capsaicin patch provides significant improvements in pain. The most commonly reported side effects were erythema, burning, or pain localized to the application site [101]. Repeated applications for up to 12 months in patients with painful HIV-associated DSPN provide continued pain relief

Table 5 Summary of cannabis as a potential treatment option for diabetic peripheral neuropathy $[63-65,69,70]$

\begin{tabular}{|c|c|c|c|}
\hline Treatment & Mechanism of action & Advantages & Disadvantages \\
\hline \multicolumn{4}{|c|}{ Cannabinoids } \\
\hline Cannabis & $\begin{array}{l}\text { Partial cannabinoid } \\
\text { receptor agonist }\end{array}$ & $\begin{array}{l}\text { - Smoked cannabis relieves } \\
\text { HIV-associated neuropathy }\end{array}$ & $\begin{array}{l}\text { - Not FDA-approved for pDPN } \\
\text { - Side effects include headache, dizziness, somnolence, } \\
\text { dry mouth, constipation, and diarrhea } \\
\text { - Cannabis spray showed no effect on painful polyneuropathy } \\
\text { - Medicolegal and regulatory hurdles } \\
\text { - Social stigma }\end{array}$ \\
\hline
\end{tabular}

$F D A$ Food and Drug Administration, $H I V$ human immunodeficiency virus, $p D P N$ painful diabetic peripheral neuropathy 


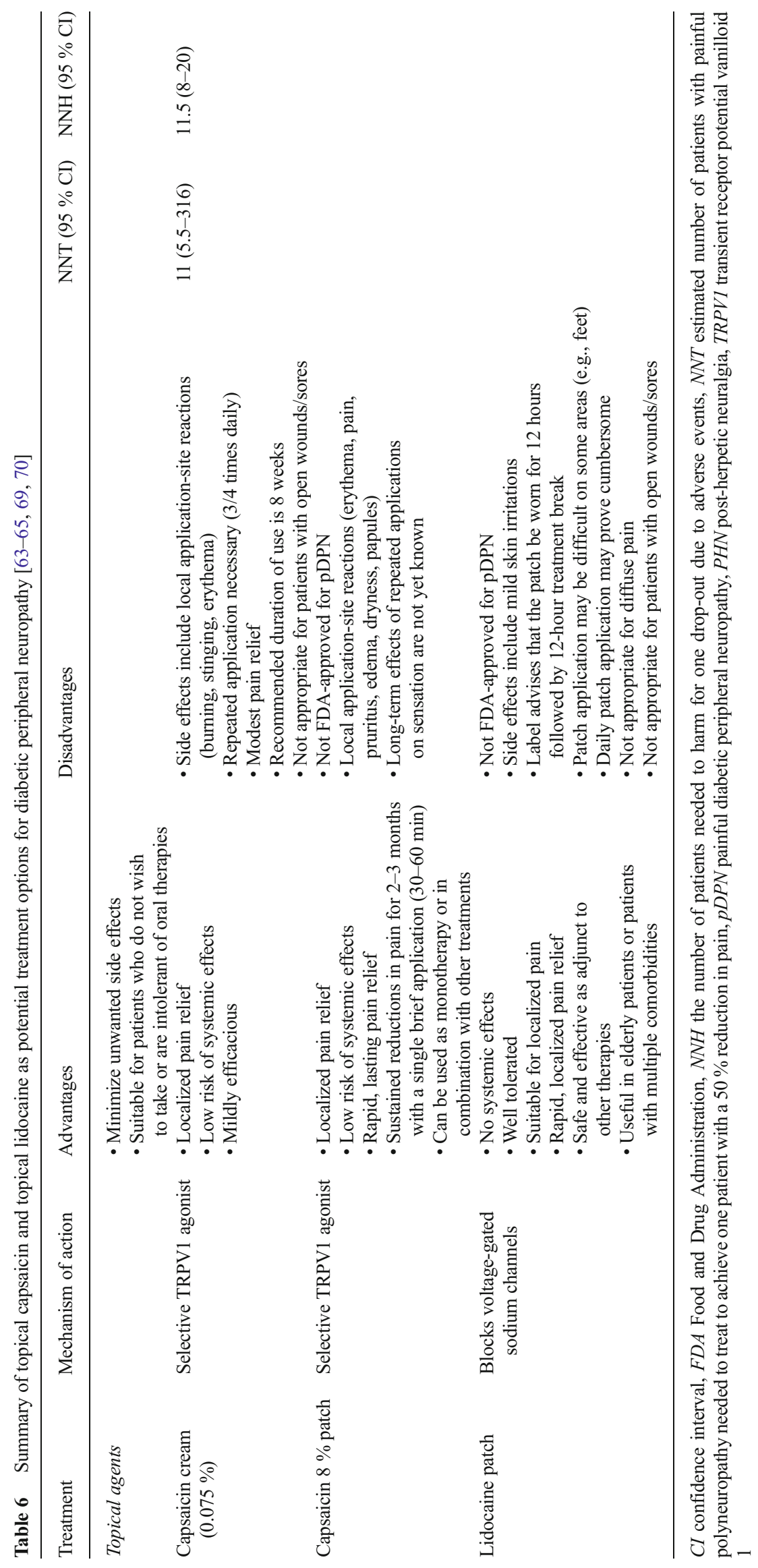


with reproducible safety and tolerability [102]. The highconcentration $8 \%$ capsaicin patch is FDA approved for PHN, and is approved in the European Union for all forms of peripheral neuropathic pain in patients without diabetes. Two controlled trials of the high-concentration $8 \%$ capsaicin patch in pDPN, NCT01533428 and NCT01478607, are completed, with results from the former showing significantly greater reductions in average daily pain scores for a single 30 -minute $8 \%$ capsaicin patch application, maintained for up to 12 weeks, compared with application of a placebo patch $(\mathrm{p}=0.018)$, and results from the latter trial expected by the end of 2015 [103, 104]. The clinical characteristics of capsaicin are summarized in Table 6.

\section{Lidocaine Patches}

Lidocaine (5\%) medicated patches are approved by the FDA for PHN. Lidocaine blocks sodium channels, so decreasing ectopic discharges. Up to four lidocaine patches may be applied per day. A comparative study indicated that lidocaine $(5 \%)$ patches are as effective as pregabalin in reducing neuropathic pain and are well tolerated [105]. Adverse effects include local skin reactions. The AAN recommends that the patch may be considered for the treatment of diabetic neuropathy, giving it a level $\mathrm{C}$ recommendation. The clinical characteristics of lidocaine are summarized in Table 6.

\section{Who Manages DSPN?}

There is considerable variability in the role of the healthcare provider who initially diagnoses and ultimately manages DSPN. It can depend on the patient's presenting symptom or primary complaint, the referral pattern of the primary care physician (PCP), and the patient's geographic location and access to specialists. As neuropathic symptoms may be the initial complaint of patients with diabetes, they may first present to neurologists, pain specialists, or podiatrists. These specialists must, therefore, recognize DSPN as an initial presenting symptom of diabetes. If the patient is not known to have diabetes, blood screening should include $\mathrm{HbA}_{1 \mathrm{c}}$ levels and an oral glucose tolerance test. As the mainstay of DSPN therapy is glycemic control, general diabetes management should remain within the realm of PCPs, endocrinologists, or diabetes specialists. One benefit of the PCP managing patients with DSPN is that they can also manage the other systemic complications of diabetes beyond neuropathy.

Most PCPs try to manage the complications of diabetes including DSPN until they face certain challenges. The 2013 NICE guidelines recommend referral to a specialist pain service or a condition-specific specialist, such as a neurologist, diabetologist, or oncologist, at any stage if the patient experiences any of the following: severe pain; pain that significantly affects their lifestyle, daily activities, and participation; or deterioration of their underlying health condition (Fig. 1) [106].

In a survey of PCPs and diabetologists, the majority of PCPs did not routinely refer their patients with diabetes to specialty diabetes care [107]. Two-thirds of PCPs reported referring less than a quarter of their patients with diabetes to specialists; reasons for referral included complications with insulin therapy and use of advanced treatment strategies. PCPs were unclear about who was responsible for diabetes management after a specialty referral. Over three-quarters of specialists thought that less than half of PCP practices managed patients with diabetes effectively, through their care or referral to specialists. Reasons were lack of time (73\%), lack of perspective on what to treat and when to refer $(69 \%)$, and lack of experience or confidence in designing treatment algorithms (68\%) [107]. The limited number of specialists in rural areas may be a barrier to accessing specialty services. Telemedicine

1. Person with neuropathic pain presents in a non-specialist setting

- Take into account the concerns and expectations of the patient

- Discuss all aspects of the patient's pain, its impact on their daily life, and the potential benefits and risks of all types of available treatment

- Take into account any comorbidities and concurrent medications, e.g.,:

- Sleep, anxiety, and depression may affect the choice of pharmacologic treatment

- Cardiovascular status of patient must be known before prescription of tricyclic antidepressants

- Consider referring the patient to a specialist pain and/or condition-specific service at any stage

- Continue existing treatments for patients whose neuropathic pain is already effectively managed

- Take overlap with old treatments into account when introducing a new treatment

- Carry out an early clinical review of dosage titration, tolerability, and adverse events after starting/changing a treatment

- Carry out regular clinical reviews to assess and monitor treatment effectiveness

- Taper the withdrawal regimen to account for dosage and any discontinuation symptoms when withdrawing/switching treatment

3. Pharmacologic treatment for all neuropathic pain (except trigeminal neuralgia)

- Offer a choice of amitriptyline, duloxetine, gabapentin, or pregabalin as intial treatment

- If initial treatment is not effective/tolerated, offer 1 of the 3 remaining drugs - Consider switching again if the $2 \mathrm{nd} / 3 \mathrm{rd}$ drugs tried are not effective/tolerated - Only consider tramadol if acute rescue therapy is needed

- Consider capsaicin cream for people with localized neuropathic pain who wish to avoid/cannot tolerate oral treatments

\section{Treatments that should not be used}

- Cannabis sativa extract, capsaicin patch, lacosamide, lamotrigine, levetiracetam, morphine, oxcarbazepine, topiramate, tramadol (for long-term use), venlafaxine

\section{Non-pharmacologic treatments in a specialist setting}

- Spinal cord stimulation (under specific conditions)

Fig. 1 Neuropathic pain pathway adapted from the UK National Institute for Health and Care Excellence [106] 
is a possible solution-a simple, cost-effective means of specialists assessing patients in remote locations. A 3D digital optical system is a reliable way of examining diabetic foot ulcers from remote settings, allowing accurate measurements of the wound [108].

There are national variations in referral patterns for patients with DSPN among PCPs. A study in the USA, the UK, and Germany found that for a patient with emerging distal neuropathy, US physicians were most active in terms of questioning, testing, prescribing, and advice giving. US and UK physicians were more likely to refer to a podiatrist than German physicians [109]. There is considerable variability in referral patterns for diabetes management among different European countries [110]. Despite these differences, there was relatively little difference in treatment regimens.

The treatment decision should be tailored to the individual patient, taking into consideration comorbidities, side effects, and drug-drug interactions. Although it is unknown whether treatment preferences differ among different types of specialists, a recent survey found that nearly half of patients with DSPN received nonsteroidal anti-inflammatory drugs (NSAIDs), in spite of their lack of efficacy, and $43 \%$ required opioids, whereas only $27 \%$ were prescribed anticonvulsants and $18 \%$ SNRIs [3]. A large proportion of patients with DSPN appears to be inappropriately treated with NSAIDs, and is over-prescribed opioids. Better education is needed for providers on the treatment of DSPN [111].

Once an ulcer is identified, treatment strategies should shift from symptomatic therapies to more aggressive interventions.
Although grade 1 ulcerations (superficial ulcerations) may be managed by a PCP by pressure relief with special footwear, bracing, or casting, grade 2 ulcerations (ulcers penetrating to tendon or capsule) or grade 3 ulcerations (ulcers penetrating to bone or joint) should be referred to a specialist, such as an orthopedic surgeon or podiatrist, for surgical treatment including debridement and possible amputation [112].

\section{Diabetes Education}

Lack of patient education - often due to the limited time during office visits - is a large barrier to active patient participation in glycemic control. Although PCPs are the primary diabetes educators in their practice, specialists appear to rely more on certified diabetes educators (CDEs). However, the proportion of established patients counseled by a CDE at least once yearly appears to be low [107].

\section{Multidisciplinary Approach}

Multidisciplinary teams (Fig. 2) may be the key to reinforcing patient education, particularly when limited time is a hurdle in the outpatient clinic. With smaller practices merging into larger group practices, the role of the multidisciplinary team is growing. In a study of patients with pDPN in a multidisciplinary outpatient setting [113], a PCP referred to a diabetologistsupervised nurse practitioner who then diagnosed and treated all patients according to strict protocols and algorithms.

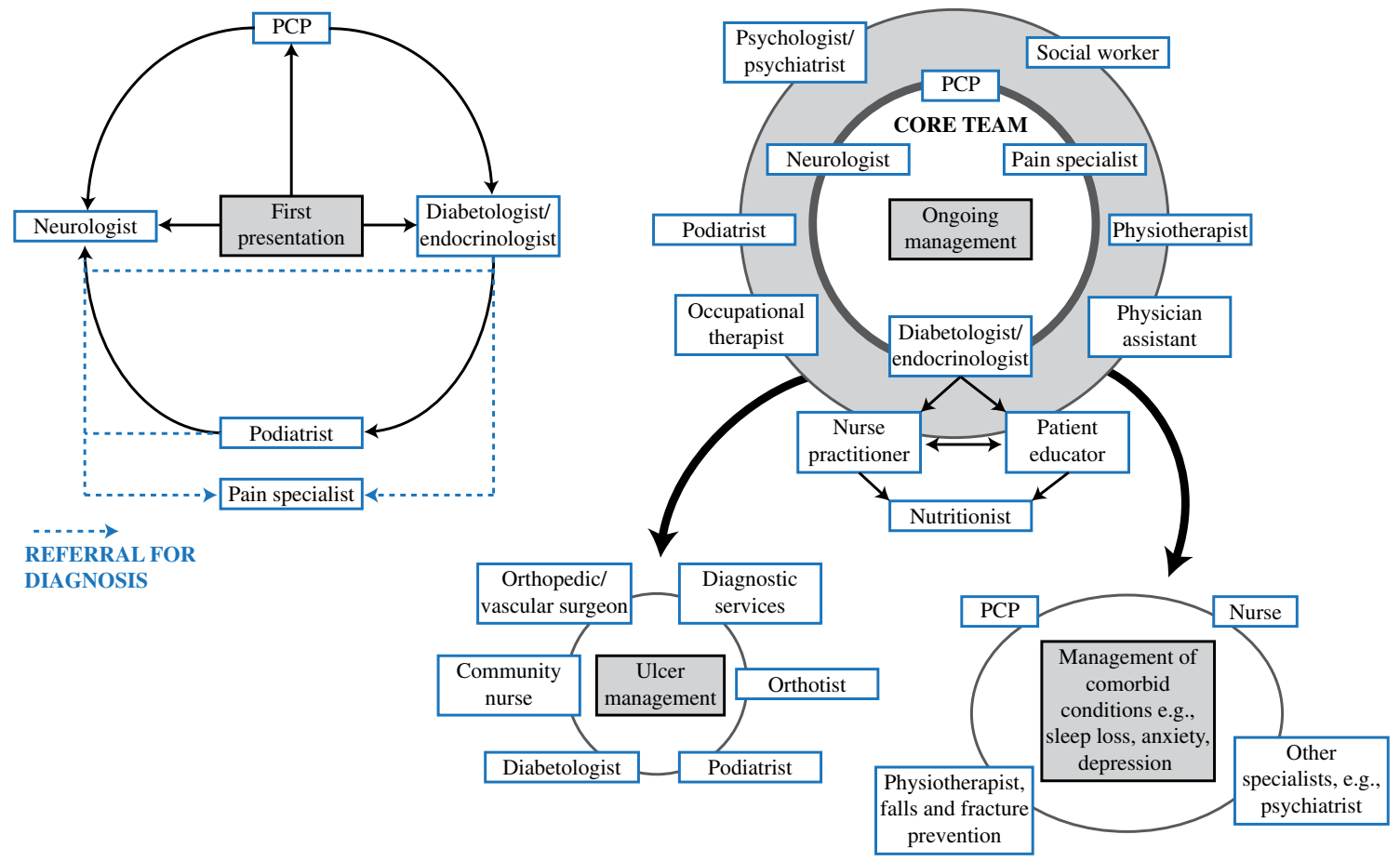

Fig. 2 Multidisciplinary team approach to the management of diabetic neuropathic pain/distal symmetric polyneuropathy. PCP—primary care physician 
Patients who did not respond to treatment were referred to a specialized outpatient pain clinic. Improvements were found in all pain scores, and in levels of pain interference in sleep, general activity, and mood. The authors concluded that a specialized outpatient clinic for patients with $\mathrm{pDPN}$ is an effective healthcare service. Enhancing the role of nursing staff within a practice has also been shown to be particularly helpful [114]. Combining a nurse, patient educator, or both with strict follow-up leads to improvements in patient care and outcomes. Nurses can serve as a liaison between patient and physician, help with patient adherence to treatment and education, and assume some responsibilities of the physician if trained with detailed protocols.

The use of multidisciplinary teams significantly decreased rates of amputation in a hospital in the UK over an 11-year period [115]. Ulcer management should include surgeons, podiatrists, orthotists, clinic-based community nurses, and diabetologists. They should have access to facilities for managing major wounds, including orthopedic or vascular surgery, and diagnostic services, such as microbiology and radiology [116]. As DSPN can be a psychosocial stressor, it is reasonable to include psychologists, social workers, and occupational therapists in the multidisciplinary team.

This multidisciplinary approach also has an economic impact, and with the advent of the Affordable Care Act in the USA, economic pressures may further limit patient access to specialty care. Various solutions have been suggested to address these issues including expanded fixed per-member permonth fees to provide specialty care; compensation models for services such as email, telephone, and curbside consultations; increasing the number of salaried employees of hospital or health systems; and increased peer education [117].

\section{Conclusions}

DSPN is the most common form of diabetic neuropathy and a significant source of patient distress, and an economic and resource burden. Complications include depression, poor sleep, foot ulcers, loss of ambulation, loss of overall function, and amputation. The primary treatment should focus on strict glycemic control and adjustment of modifiable risk factors. There are currently no curative therapies, and symptomatic treatments are recommended by various professional societies. Barriers to effective management include failure to recognize DSPN, particularly when it is asymptomatic. Patients may be in denial of their disease and refuse to actively seek treatment or become noncompliant with medications and interventions.

DSPN is managed in several settings by PCPs, specialists, and nurse practitioners. Management should include patient education, including foot self-examinations, and lifestyle modifications, such as smoking cessation, healthy diet, and exercise. Because strict glycemic control is the mainstay of DSPN treatment, a PCP, endocrinologist, or diabetologist should be involved in care. Referral patterns vary widely according to geographic location, access to services, provider preferences, and physician comfort in managing complex aspects of the disease. The patient should understand the various provider roles and who to address with specific questions. The role of standardized screening tools, the multidisciplinary team, and models utilizing trained nurse practitioners following a neuropathy treatment algorithm are all possible solutions in the streamlining and improvement of future care. Moving forward, physicians should make earlier diagnoses and intervene before significant nerve damage occurs.

Acknowledgments Editorial assistance was provided by Adelphi Communications Ltd, supported by Astellas Pharma Europe Ltd. Development of the manuscript was carried out in accordance with Good Publication Practice 2 guidelines. All authors contributed at all stages to the writing and revision of the manuscript for intellectual content and have reviewed and approved the final version for submission.

\section{Compliance with Ethics Guidelines}

Conflict of Interest Michelle Kaku declares that she has no conflict of interest.

Aaron Vinik is a consultant for and received honoraria from ISIS Pharmaceuticals, Merck, Pamlabs, and Pfizer. He has research grants from Pfizer, Tercica, ViroMed, Daiichi Sankyo Intarcia, Impeto Medical and VeroScience.

David M. Simpson is consultant for Acorda and Astellas and has received research grants from Acorda, Astellas, Pfizer, and Viromed.

Human and Animal Rights and Informed Consent This article does not contain any studies with human or animal subjects performed by any of the authors.

Open Access This article is distributed under the terms of the Creative Commons Attribution 4.0 International License (http:// creativecommons.org/licenses/by/4.0/), which permits unrestricted use, distribution, and reproduction in any medium, provided you give appropriate credit to the original author(s) and the source, provide a link to the Creative Commons license, and indicate if changes were made.

\section{References}

Papers of particular interest, published recently, have been highlighted as:

- Of importance

•- Of major importance

1. Barrett AM, Lucero MA, Le T, et al. Epidemiology, public health burden, and treatment of diabetic peripheral neuropathic pain: a review. Pain Med. 2007;8 Suppl 2:S50-62.

2. Vileikyte L, Peyrot M, Gonzalez JS, et al. Predictors of depressive symptoms in persons with diabetic peripheral neuropathy: a longitudinal study. Diabetologia. 2009;52:1265-73.

3. Sadosky A, Schaefer C, Mann R, et al. Burden of illness associated with painful diabetic peripheral neuropathy among adults 
seeking treatment in the US: results from a retrospective chart review and cross-sectional survey. Diabetes Metab Syndr Obes. 2013;6:79-92.

4. Gordois A, Scuffham P, Shearer A, et al. The health care costs of diabetic peripheral neuropathy in the US. Diabetes Care. 2003;26: $1790-5$.

5. Moser JT, Langdon DR, Finkel RS, et al. The evaluation of peripheral neuropathy in youth with type 1 diabetes. Diabetes Res Clin Pract. 2013;100:e3-6.

6. Karabouta Z, Barnett S, Shield JP, et al. Peripheral neuropathy is an early complication of type 2 diabetes in adolescence. Pediatr Diabetes. 2008;9:110-4.

7. Thomas PK. Classification, differential diagnosis, and staging of diabetic peripheral neuropathy. Diabetes. 1997;46 Suppl 2:S54-7.

8. Boulton AJ, Vinik AI, Arezzo JC, et al. Diabetic neuropathies: a statement by the American Diabetes Association. Diabetes Care. 2005;28:956-62.

9. Tesfaye S, Boulton AJ, Dyck PJ, et al. Diabetic neuropathies: update on definitions, diagnostic criteria, estimation of severity, and treatments. Diabetes Care. 2010;33:2285-93.

10. Apfel SC, Asbury AK, Bril V, et al. Positive neuropathic sensory symptoms as endpoints in diabetic neuropathy trials. J Neurol Sci. 2001;189:3-5.

11. Papanas N, Vinik AI, Ziegler D. Neuropathy in prediabetes: does the clock start ticking early? Nat Rev Endocrinol. 2011;7:682-90.

12. Sharma KR, Cross J, Farronay O, et al. Demyelinating neuropathy in diabetes mellitus. Arch Neurol. 2002;59:758-65.

13. van Deursen RW, Sanchez MM, Ulbrecht JS, et al. The role of muscle spindles in ankle movement perception in human subjects with diabetic neuropathy. Exp Brain Res. 1998;120:1-8.

14. Morrison S, Colberg SR, Mariano M, et al. Balance training reduces falls risk in older individuals with type 2 diabetes. Diabetes Care. 2010;33:748-50.

15. Abbott CA, Carrington AL, Ashe $\mathrm{H}$, et al. The North-West Diabetes Foot Care Study: incidence of, and risk factors for, new diabetic foot ulceration in a community-based patient cohort. Diabet Med. 2002;19:377-84.

16. Singh N, Armstrong DG, Lipsky BA. Preventing foot ulcers in patients with diabetes. JAMA. 2005;293:217-28.

17. Vinik AI, Casellini CM. Guidelines in the management of diabetic nerve pain: clinical utility of pregabalin. Diabetes Metab Syndr Obes. 2013;6:57-78.

18. The Diabetes Control and Complications Trial Research Group. The effect of intensive diabetes therapy on the development and progression of neuropathy. Ann Intern Med. 1995;122:561-8.

19. Albers JW, Herman WH, Pop-Busui R, et al. Effect of prior intensive insulin treatment during the Diabetes Control and Complications Trial (DCCT) on peripheral neuropathy in type 1 diabetes during the Epidemiology of Diabetes Interventions and Complications (EDIC) Study. Diabetes Care. 2010;33:1090-6.

20.• Martin CL, Albers JW, Pop-Busui R, et al. Neuropathy and related findings in the diabetes control and complications trial/ epidemiology of diabetes interventions and complications study. Diabetes Care. 2014;37:31-8. This article reports the findings of the Epidemiology of Diabetes Interventions and Complications (EDIC) study, and discusses the clinical course of diabetic neuropathy and how it can be prevented.

21. Tesfaye S, Stevens LK, Stephenson JM, et al. Prevalence of diabetic peripheral neuropathy and its relation to glycaemic control and potential risk factors: the EURODIAB IDDM Complications Study. Diabetologia. 1996;39:1377-84.

22. Dyck PJ, Clark VM, Overland CJ, et al. Impaired glycemia and diabetic polyneuropathy: the OC IG Survey. Diabetes Care. 2012;35:584-91.
23. Bongaerts BW, Rathmann W, Kowall B, et al. Postchallenge hyperglycemia is positively associated with diabetic polyneuropathy: the KORA F4 study. Diabetes Care. 2012;35:1891-3.

24. Smith AG, Russell J, Feldman EL, et al. Lifestyle intervention for pre-diabetic neuropathy. Diabetes Care. 2006;29:1294-9.

25. Stratton IM, Adler AI, Neil HA, et al. Association of glycaemia with macrovascular and microvascular complications of type 2 diabetes (UKPDS 35): prospective observational study. BMJ. 2000;321:405-12.

26. Gibbons CH, Freeman R. Treatment-induced diabetic neuropathy: a reversible painful autonomic neuropathy. Ann Neurol. 2010;67: 534-41.

27. Vinik AI, Erbas T, Casellini CM. Diabetic cardiac autonomic neuropathy, inflammation and cardiovascular disease. J Diabetes Investig. 2013;4:4-18.

28. Calles-Escandón J, Lovato LC, Simons-Morton DG, et al. Effect of intensive compared with standard glycemia treatment strategies on mortality by baseline subgroup characteristics: the Action to Control Cardiovascular Risk in Diabetes (ACCORD) trial. Diabetes Care. 2010;33:721-7.

29. Vinik AI, Maser RE, Ziegler D. Neuropathy: the crystal ball for cardiovascular disease? Diabetes Care. 2010;33:1688-90.

30. Llewelyn JG, Gilbey SG, Thomas PK, et al. Sural nerve morphometry in diabetic autonomic and painful sensory neuropathy. A clinicopathological study. Brain. 1991;114:867-92.

31. Archer AG, Watkins PJ, Thomas PK, et al. The natural history of acute painful neuropathy in diabetes mellitus. J Neurol Neurosurg Psychiatry. 1983;46:491-9.

32. Fernyhough P, Roy Chowdhury SK, Schmidt RE. Mitochondrial stress and the pathogenesis of diabetic neuropathy. Expert Rev Endocrinol Metab. 2010;5:39-49.

33. Stavniichuk R, Drel VR, Shevalye H, et al. Role of 12/15lipoxygenase in nitrosative stress and peripheral prediabetic and diabetic neuropathies. Free Radic Biol Med. 2010;49:1036-45.

34. Stavniichuk R, Shevalye H, Lupachyk S, et al. Peroxynitrite and protein nitration in the pathogenesis of diabetic peripheral neuropathy. Diabetes Metab Res Rev. 2014;30:669-78.

35. Obrosova IG. Increased sorbitol pathway activity generates oxidative stress in tissue sites for diabetic complications. Antioxid Redox Signal. 2005;7:1543-52.

36. Kim B, Feldman EL. Insulin resistance in the nervous system. Trends Endocrinol Metab. 2012;23:133-41.

37. Callaghan BC, Cheng HT, Stables CL, et al. Diabetic neuropathy: clinical manifestations and current treatments. Lancet Neurol. 2012;11:521-34. This review outlines the clinical characteristics of diabetic neuropathy and provides an overview of analgesic treatment options, it also discusses potential future areas for research, with a particular focus on metabolic syndrome and the prevention of diabetic neuropathy.

38. Vinik AI, Nevoret ML, Casellini C, et al. Diabetic neuropathy. Endocrinol Metab Clin North Am. 2013;42:747-87. This comprehensive review discusses both the distinguishing characteristics of different types of neuropathy and the management of diabetic neuropathic pain. The review also gives background on the epidemiology and pathophysiology of diabetic neuropathy.

39. Baron R, Hans G, Dickenson AH. Peripheral input and its importance for central sensitization. Ann Neurol. 2013;74:630-6.

40. Vinik A. The approach to the management of the patient with neuropathic pain. J Clin Endocrinol Metab. 2010;95:4802-11.

41. Bourcier ME, Ullal J, Parson HK, et al. Diabetic peripheral neuropathy: how reliable is a homemade 1-g monofilament for screening? J Fam Pract. 2006;55:505-8.

42. O'Brien T, Karem J. Relative sensory sparing in the diabetic foot implied through vibration testing. Diabet Foot Ankle. 2013;4. 
43. Tavee J, Zhou L. Small fiber neuropathy: a burning problem. Cleve Clin J Med. 2009;76:297-305.

44. McArthur JC, Stocks EA, Hauer P, et al. Epidermal nerve fiber density: normative reference range and diagnostic efficiency. Arch Neurol. 1998;55:1513-20.

45. Gibbons $\mathrm{CH}$, Griffin JW, Polydefkis M, et al. The utility of skin biopsy for prediction of progression in suspected small fiber neuropathy. Neurology. 2006;66:256-8.

46. Devigili G, Tugnoli V, Penza P, et al. The diagnostic criteria for small fibre neuropathy: from symptoms to neuropathology. Brain. 2008;131:1912-25.

47. Young RJ, Ewing DJ, Clarke BF. Chronic and remitting painful diabetic polyneuropathy. Correlations with clinical features and subsequent changes in neurophysiology. Diabetes Care. 1988;11: 34- 40 .

48. Leishear K, Boudreau RM, Studenski SA, et al. Relationship between vitamin B12 and sensory and motor peripheral nerve function in older adults. J Am Geriatr Soc. 2012;60:1057-63.

49. Fonseca VA, Lavery LA, Thethi TK, et al. Metanx in type 2 diabetes with peripheral neuropathy: a randomized trial. Am J Med. 2013;126:141-9.

50. Dyck PJ, Albers JW, Andersen H, et al. Diabetic polyneuropathies: update on research definition, diagnostic criteria and estimation of severity. Diabetes Metab Res Rev. 2011;27:620-8.

51. Feldman EL, Stevens MJ, Thomas PK, et al. A practical two-step quantitative clinical and electrophysiological assessment for the diagnosis and staging of diabetic neuropathy. Diabetes Care. 1994;17:1281-9.

52. Melzack R. The short-form McGill Pain Questionnaire. Pain. 1987;30:191-7.

53. Krause SJ, Backonja MM. Development of a neuropathic pain questionnaire. Clin J Pain. 2003;19:306-14.

54. Zelman DC, Gore M, Dukes E, et al. Validation of a modified version of the Brief Pain Inventory for painful diabetic peripheral neuropathy. J Vasc Nurs. 2005;23:97-104.

55. Bouhassira D, Attal N, Fermanian J, et al. Development and validation of the Neuropathic Pain Symptom Inventory. Pain. 2004;108:248-57.

56. Boyd A, Casselini C, Vinik E, et al. Quality of life and objective measures of diabetic neuropathy in a prospective placebocontrolled trial of ruboxistaurin and topiramate. J Diabetes Sci Technol. 2011;5:714-22.

57. Vileikyte L, Peyrot M, Bundy C, et al. The development and validation of a neuropathy- and foot ulcer-specific quality of life instrument. Diabetes Care. 2003;26:2549-55.

58. Votrubec M, Thong I. Neuropathic pain - a management update. Aust Fam Physician. 2013;42:92-7.

59. Robertson RP, Sutherland DE. Pancreas transplantation as therapy for diabetes mellitus. Annu Rev Med. 1992;43:395-415.

60. Boyd AL, Barlow PM, Pittenger GL, et al. Topiramate improves neurovascular function, epidermal nerve fiber morphology, and metabolism in patients with type 2 diabetes mellitus. Diabetes Metab Syndr Obes. 2010;3:431-7.

61. Tesfaye S, Vileikyte L, Rayman G, et al. Painful diabetic peripheral neuropathy: consensus recommendations on diagnosis, assessment and management. Diabetes Metab Res Rev. 2011;27: 629-38. This comprehensive review of painful diabetic neuropathy includes discussion on both the diagnosis and treatment of diabetic neuropathy, as well as highlighting some of the limitations of the existing evidence base supporting these treatments.

62. Dworkin $\mathrm{RH}, \mathrm{O} \mathrm{O}^{\mathrm{C}}$ onnor $\mathrm{AB}, \mathrm{Kent} \mathrm{J}$, et al. Interventional management of neuropathic pain: NeuPSIG recommendations. Pain. 2013;154:2249-61.
63. Attal N, Cruccu G, Baron R, et al. EFNS guidelines on the pharmacological treatment of neuropathic pain: 2010 revision. Eur J Neurol. 2010;17:1113-23.

64. National Institute for Health and Clinical Excellence. Neuropathic pain - pharmacological management: the pharmacological management of neuropathic pain in adults in non-specialist settings. 2013. http://www.nice.org.uk/guidance/cg173. Accessed 24 June 2014

65. Bril V, England J, Franklin GM, et al. Evidence-based guideline: treatment of painful diabetic neuropathy: report of the American Academy of Neurology, the American Association of Neuromuscular and Electrodiagnostic Medicine, and the American Academy of Physical Medicine and Rehabilitation. Neurology. 2011;76:1758-65.

66. Hartemann A, Attal N, Bouhassira D, et al. Painful diabetic neuropathy: diagnosis and management. Diabetes Metab. 2011;37: 377-88.

67. Handelsman Y, Mechanick JI, Blonde L, et al. American Association of Clinical Endocrinologists Medical Guidelines for Clinical Practice for developing a diabetes mellitus comprehensive care plan. Endocr Pract. 2011;17 Suppl 2:1-53.

68. Spallone V. Management of painful diabetic neuropathy: guideline guidance or jungle? Curr Diab Rep. 2012;12:403-13.

69. Dworkin RH, O'Connor AB, Audette J, et al. Recommendations for the pharmacological management of neuropathic pain: an overview and literature update. Mayo Clin Proc. 2010;85(3 Suppl):S3-14.

70. Finnerup NB, Sindrup SH, Jensen TS. The evidence for pharmacological treatment of neuropathic pain. Pain. 2010;150:573-81.

71. Raskin J, Smith TR, Wong K, et al. Duloxetine versus routine care in the long-term management of diabetic peripheral neuropathic pain. J Palliat Med. 2006;9:29-40.

72. Rull JA, Quibrera R, González-Millán H, et al. Symptomatic treatment of peripheral diabetic neuropathy with carbamazepine (Tegretol): double blind crossover trial. Diabetologia. 1969;5: $215-8$.

73. Wilton TD. Tegretol in the treatment of diabetic neuropathy. S Afr Med J. 1974:48:869-72.

74. Jose VM, Bhansali A, Hota D, et al. Randomized double-blind study comparing the efficacy and safety of lamotrigine and amitriptyline in painful diabetic neuropathy. Diabet Med. 2007;24: 377-83.

75. Eisenberg E, Lurie Y, Braker C, et al. Lamotrigine reduces painful diabetic neuropathy: a randomized, controlled study. Neurology. 2001;57:505-9.

76. Vinik AI, Tuchman M, Safirstein B, et al. Lamotrigine for treatment of pain associated with diabetic neuropathy: results of two randomized, double-blind, placebo-controlled studies. Pain. 2007;128:169-79.

77. Silver M, Blum D, Grainger J, et al. Double-blind, placebocontrolled trial of lamotrigine in combination with other medications for neuropathic pain. J Pain Symptom Manage. 2007;34: 446-54.

78. Vinik A, Emir B, Cheung R, et al. Relationship between pain relief and improvements in patient function/quality of life in patients with painful diabetic peripheral neuropathy or postherpetic neuralgia treated with pregabalin. Clin Ther. 2013;35:612-23.

79. Freeman R, Raskin P, Hewitt DJ, et al. Randomized study of tramadol/acetaminophen versus placebo in painful diabetic peripheral neuropathy. Curr Med Res Opin. 2007;23:147-61.

80. Harati Y, Gooch C, Swenson M, et al. Double-blind randomized trial of tramadol for the treatment of the pain of diabetic neuropathy. Neurology. 1998;50:1842-6.

81. Schwartz S, Etropolski M, Shapiro DY, et al. Safety and efficacy of tapentadol ER in patients with painful diabetic peripheral 
neuropathy: results of a randomized-withdrawal, placebocontrolled trial. Curr Med Res Opin. 2011;27:151-62.

82. Vinik AI, Shapiro DY, Rauschkolb C, et al. A randomized-withdrawal, placebo-controlled study evaluating the efficacy and tolerability of tapentadol extended release in patients with chronic, painful diabetic peripheral neuropathy. Diabetes Care. 2014;37: 2302-9.

83. Janssen Pharmaceuticals I. Highlights of prescribing information: Nucynta ${ }^{\circledR}$ ER (tapentadol) extended-release oral tablets C-II. 2014. https://www.nucynta.com/shared/product/nucynta/ nucyntaer-pi.pdf. Accessed 24 June 2014

84. Simpson DM, Messina J, Xie F, et al. Fentanyl buccal tablet for the relief of breakthrough pain in opioid-tolerant adult patients with chronic neuropathic pain: a multicenter, randomized, doubleblind, placebo-controlled study. Clin Ther. 2007;29:588-601.

85. Ko SH, Kwon HS, Yu JM, et al. Comparison of the efficacy and safety of tramadol/acetaminophen combination therapy and gabapentin in the treatment of painful diabetic neuropathy. Diabet Med. 2010;27:1033-40.

86. Hanna M, O’Brien C, Wilson MC. Prolonged-release oxycodone enhances the effects of existing gabapentin therapy in painful diabetic neuropathy patients. Eur J Pain. 2008;12:804-13.

87. Gilron I, Bailey JM, Tu D, et al. Morphine, gabapentin, or their combination for neuropathic pain. N Engl J Med. 2005;352:1324-34.

88. Zin CS, Nissen LM, O'Callaghan JP, et al. A randomized, controlled trial of oxycodone versus placebo in patients with postherpetic neuralgia and painful diabetic neuropathy treated with pregabalin. J Pain. 2010;11:462-71.

89. Ellis RJ, Toperoff W, Vaida F, et al. Smoked medicinal cannabis for neuropathic pain in HIV: a randomized, crossover clinical trial. Neuropsychopharmacology. 2009;34:672-80.

90. Abrams DI, Jay CA, Shade SB, et al. Cannabis in painful HIVassociated sensory neuropathy: a randomized placebo-controlled trial. Neurology. 2007;68:515-21.

91. Selvarajah D, Gandhi R, Emery CJ, et al. Randomized placebocontrolled double-blind clinical trial of cannabis-based medicinal product (Sativex) in painful diabetic neuropathy: depression is a major confounding factor. Diabetes Care. 2010;33:128-30.

92. Mijnhout GS, Kollen BJ, Alkhalaf A, et al. Alpha lipoic acid for symptomatic peripheral neuropathy in patients with diabetes: a meta-analysis of randomized controlled trials. Int J Endocrinol. 2012;2012:456279.

93. Ziegler D, Low PA, Litchy WJ, et al. Efficacy and safety of antioxidant treatment with alpha-lipoic acid over 4 years in diabetic polyneuropathy: the NATHAN 1 trial. Diabetes Care. 2011;34: 2054-60.

94. Ziegler D, Ametov A, Barinov A, et al. Oral treatment with alphalipoic acid improves symptomatic diabetic polyneuropathy: the SYDNEY 2 trial. Diabetes Care. 2006;29:2365-70.

95. Han T, Bai J, Liu W, et al. A systematic review and meta-analysis of $\alpha$-lipoic acid in the treatment of diabetic peripheral neuropathy. Eur J Endocrinol. 2012;167:465-71.

96. Tandan R, Lewis GA, Krusinski PB, et al. Topical capsaicin in painful diabetic neuropathy. Controlled study with long-term follow-up. Diabetes Care. 1992;15:8-14.

97. The Capsaicin Study Group. Treatment of painful diabetic neuropathy with topical capsaicin. A multicenter, double-blind, vehiclecontrolled study. Arch Intern Med. 1991;151:2225-9.

98. Backonja M, Wallace MS, Blonsky ER, et al. NGX-4010, a highconcentration capsaicin patch, for the treatment of postherpetic neuralgia: a randomised, double-blind study. Lancet Neurol. 2008;7:1106-12.

99. Irving GA, Backonja MM, Dunteman E, et al. A multicenter, randomized, double-blind, controlled study of NGX-4010, a high-concentration capsaicin patch, for the treatment of postherpetic neuralgia. Pain Med. 2011;12:99-109.
100. Simpson DM, Brown S, Tobias J. Controlled trial of highconcentration capsaicin patch for treatment of painful HIV neuropathy. Neurology. 2008;70:2305-13.

101. Derry S, Sven-Rice A, Cole P, et al. Topical capsaicin (high concentration) for chronic neuropathic pain in adults. Cochrane Database Syst Rev. 2013;2:CD007393

102. Simpson DM, Brown S, Tobias JK, et al. NGX-4010, a capsaicin $8 \%$ dermal patch, for the treatment of painful HIV-associated distal sensory polyneuropathy: results of a 52-week open-label study. Clin J Pain. 2014;30:134-42.

103. Stoker M, Jacobs H, Lloyd A, et al. A Phase 3, double-blind, randomized, placebo-controlled, multicenter study evaluating the efficacy and safety of QUTENZA ${ }^{\circledR}$ (high concentration $8 \%$ capsaicin patch) in subjects with painful diabetic peripheral neuropathy (pDPN). Abstract presented at the 4th Biannual International Multidisciplinary Pain Congress, Eindhoven, Netherlands; October 1-4, 2014. Abstract 51.

104. Astellas Pharma Inc. A study to evaluate the long-term safety of repeated QUTENZA administration for treatment of pain caused by nerve damage in diabetic patients (PACE). 2014. http:/ clinicaltrials.gov/ct2/show/NCT01478607?term=capsaicin+ AND+diabetes\&rank=4. Accessed 24 June 2014.

105. Baron R, Mayoral V, Leijon G, et al. Efficacy and safety of combination therapy with $5 \%$ lidocaine medicated plaster and pregabalin in post-herpetic neuralgia and diabetic polyneuropathy. Curr Med Res Opin. 2009;25:1677-87.

106. National Institute for Health and Clinical Excellence. Neuropathic pain overview: pathway. http://pathways.nice.org.uk/pathways/ neuropathic-pain. Accessed 24 June 2014.

107. Beaser RS, Okeke E, Neighbours J, et al. Coordinated primary and specialty care for type 2 diabetes mellitus, guidelines, and systems: an educational needs assessment. Endocr Pract. 2011;17:880-90.

108. Bowling FL, King L, Paterson JA, et al. Remote assessment of diabetic foot ulcers using a novel wound imaging system. Wound Repair Regen. 2011;19:25-30.

109. von dem Knesebeck O, Gerstenberger E, Link C, et al. Differences in the diagnosis and management of type 2 diabetes in 3 countries (US, UK, and Germany): results from a factorial experiment. Med Care. 2010;48:321-6.

110. Donker GA, Fleming DM, Schellevis FG, et al. Differences in treatment regimes, consultation frequency and referral patterns of diabetes mellitus in general practice in five European countries. Fam Pract. 2004;21:364-9.

111. Iyer S, Tanenberg RJ. Pharmacologic management of diabetic peripheral neuropathic pain. Expert Opin Pharmacother. 2013;14: 1765-75.

112. Farber DC, Farber JS. Office-based screening, prevention, and management of diabetic foot disorders. Prim Care. 2007;34:87385 .

113. Geerts M, Landewe-Cleuren SA, Kars M, et al. Effective pharmacological treatment of painful diabetic neuropathy by nurse practitioners: results of an algorithm-based experience. Pain Med. 2012;13:1324-33.

114. Renders CM, Valk GD, Griffin SJ, et al. Interventions to improve the management of diabetes in primary care, outpatient, and community settings: a systematic review. Diabetes Care. 2001;24: 1821-33.

115. Krishnan S, Nash F, Baker N, et al. Reduction in diabetic amputations over 11 years in a defined U.K. population: benefits of multidisciplinary team work and continuous prospective audit. Diabetes Care. 2008;31:99-101.

116. Malik RA, Tesfaye S, Ziegler D. Medical strategies to reduce amputation in patients with type 2 diabetes. Diabet Med. 2013;30:893-900.

117. Landon BE, Roberts DH. Reenvisioning specialty care and payment under global payment systems. JAMA. 2013;310:371-2. 